\title{
Promessa tecnológica e vantagem combatente
}

\author{
Technological promise and fighting advantage
}

DOMÍCIO PROENÇA JÚNIOR*

Rev. Bras. Polít. Int. 54 (2): 173-188 [2011]

Máquinas não vencem batalhas, mesmo que se ganhem batalhas com máquinas uma enorme diferença. Ernst Jünger, Das Wäldchen 125 (Berlin, 1926)

\section{Introdução}

Mais ou melhor tecnologia não garante mais ou melhores arranjos de defesa. A ênfase tecnológica expressa, por exemplo, na meta dos EUA de Transformação ou na Estratégia Nacional de Defesa do Brasil presume uma passagem fluente desde a busca por resultados tecnológicos até sua materialização em termos de arranjos de defesa. Pautar prioridades de defesa por metas tecnológicas arrisca perder de vista a integridade do processo pelo qual se busca, produz e aproveita algum resultado tecnológico para produzir capacidade combatente; pelo qual se concebe, propóe e escolhe alternativas de capacidade combatente para compor arranjos de defesa; e ainda pelo qual se aprecia e pondera a oportunidade, propriedade e utilidade de tais arranjos diante das metas e preferências políticas, por exemplo, numa política de defesa. ${ }^{1}$

Nenhum desses passos pode ser tomado como certo, nenhuma dessas passagens pode ser tomada como sendo automática, e uns e outras incluem mais do que apenas soluções tecnológicas. Cada passo e passagem tem demandas, riscos, dinâmicas e prazos próprios, considerando diversos tipos de insumos e se pautando por diferentes mecanismos. Não se pode dar como certo que se chegue ao resultado tecnológico que se deseje nos termos, prazos e custos que se

\footnotetext{
* Coordenador do Grupo de Estudos Estratégicos, Professor do Programa de Engenharia de Produção do Instituto Alberto Luiz Coimbra de Pós-Graduação e Pesquisa de Engenharia (Coppe) e do Programa de Políticas Públicas, Estratégias e Desenvolvimento do Instituto de Economia (IE) da Universidade Federal do Rio de Janeiro (UFRJ).

1 DAVIS, Paul K. (2010) 2. Military Transformation? Which Transformation, and What lies ahead? In: CIMBALA, Stephen. J. (ED.) The George W Bush Defense Program: policy, strategy \& war. Washington DC: Potomac Books, 2010. p. 11-41, 254-9; ÁVILA, Fabrício S., MARTINS, José M. \& CEPIK, Marco. (2009) Armas estratégicas e poder no sistema internacional. Contexto Internacional, Vol. 31, no 1, p. 49-83.
} 
gostaria de ter. Mesmo que se chegue a resultados tecnológicos aceitáveis, não se pode presumir que seu aproveitamento, operacionalização e sustentação em termos combatentes atendam às expectativas de capacidade que se ambiciona. Mesmo que se tenham alternativas de capacidade aceitáveis, não se pode afirmar que correspondam precisamente aos arranjos de defesa que atendam às metas e preferências políticas de um governo. Erigir a tecnologia em símbolo do que se busca e a pesquisa tecnológica como método pelo qual se buscam resultados de defesa arrisca subtrair recursos e comprometer a viabilidade do processo integral de que os arranjos de defesa dependem. ${ }^{2}$

A composição da lógica política com a gramática dos meios é a forma pela qual se pode enquadrar, articular e conduzir esse processo. A lógica política dá conta dos fins, metas e preferências de um governo, os termos pelos quais ele propóe conduzir os assuntos em que o uso de força pode ser uma consideração, como, por exemplo, a defesa. Expressa a um só tempo um diagnóstico e um prognóstico quanto a relacionamentos políticos, disponibilidades de recursos, e metas a serem perseguidas. Isso corresponde ao que se enuncia em políticas públicas de assuntos de segurança, de relações exteriores, de relações federativas e de defesa. As metas dessas políticas, a seu turno, intimam a necessidade de se terem determinadas capacidades para que possa fazer isto ou aquilo, desta ou daquela maneira, em tal alcance ou tempo. Mas isso não é o suficiente; querer não é poder. É necessário considerar a gramática dos meios, apreciando o que o estado da arte permite e, daí, o que se exige para dispor dos meios que oferecem esta ou aquela capacidade. Isso faz com que se tenha que lidar não apenas com a posse de uma determinada capacidade pronta que os meios ofereceriam, mas também com a temporalidade do preparo de tal capacidade. É com esse enquadramento que se pode delinear de forma consistente o processo que vai desde tecnologia até a posse de meios em arranjos de defesa. Seu início é a percepção do potencial de promessas tecnológicas, e seu destino seria, a um primeiro olhar, a posse de capacidade combatente pronta. ${ }^{3}$

Mas não basta considerar capacidades combatentes em si mesmas, como se elas se fizessem tecnicamente autárquicas em relação à sua destinação política uma vez escolhidas. A lógica política, que usa dessas alternativas para modificar suas metas, dá ainda destino às alternativas de arranjos de defesa, ao contextualizar o emprego dos meios que se escolhe preparar. $\mathrm{O}$ antagonismo político que considera usar de força tem lugar entre oponentes, cada um com suas capacidades. $\mathrm{O}$ destino real de todo o processo, então, diz respeito à capacidade combatente comparada, isto é, ele expressa a busca por vantagens combatentes, com tudo o que isso tem de transiente e fugidio. ${ }^{4}$

O propósito deste artigo é delinear as relações entre promessa tecnológica e vantagem combatente. Apresenta, inicialmente, alguns aspectos que balizam

2 SPINNEY, Franklin. (1985) Defense Facts of Life. Westview, 260 p.; Autor, 2007.

3 DAVIS, Paul, Ed. (1995) New Challenges for Defense Planning. Rand Publishing, 1995, 778 p.

4 MILlET, Alan R. \& MURRAY, William. (2007) Calculations. Free Press, 2007, 356 p. 
esse processo, qualificando entendimentos relativos ao papel da tecnologia na guerra e destacando a centralidade do projeto de força. Oferece, em seguida, uma ilustração histórica que pode servir para enquadrar algumas coisas sobre as quais se deve pensar. Ao final, ainda que não se possa apontar para uma conclusão cabal, espera-se ter demarcado de maneira útil aspectos essenciais do que o tema exigiria para sua correta apreciação.

\section{Tecnologia e projeto de força}

Numa era que glorifica a tecnologia, é sempre difícil questionar a expectativa de promessas tecnológicas. Isso é ainda mais delicado quando se reconhece a prevalência da miopia fácil e sensível que só vê tecnologia de produto, deixando de lado a tecnologia de processo, e a tecnologia na e da capacitação de pessoal. Esse equívoco tende a ser mais presente em assuntos de defesa do que em outros, em função da lógica de venda de seus produtos mais destacados - sistemas de armamentos (weapons systems). Qualificar o papel da tecnologia na guerra se inicia pela denúncia da falácia reducionista pela qual mais ou melhor tecnologia de produto, de artefatos, de armamentos bastaria para assegurar sucesso e vitória. Muito da dificuldade de fazê-lo reflete o fato de que um erro é tão mais perigoso quanto mais verdade inclua.

Vitória no combate, bom resultado na guerra, sucesso quando o uso da força tem lugar dependem, sim, em diferentes medidas em distintos contextos, dos armamentos e portanto da tecnologia que estes contenham. A falácia do reducionismo tecnológico simplifica tudo o mais ao redor dessa parte da verdade. Isso é especialmente sedutor, tanto por sua singeleza quanto por sua dramaticidade. Serve, por exemplo, tanto a propósitos de marketing na venda de produtos de uso de defesa quanto ainda para fins de entretenimento. Por um ou por outro motivo, a falácia de que os armamentos lutam, e mais que lutam, determinam os resultados da luta, está presente de forma marcante no imaginário do que seja a guerra. A espada que tudo corta, o escudo no qual nada penetra; o míssil que vai mais longe, o tiro que nunca erra seu alvo; o deslumbre da velocidade de uma aeronave, da imponência de um grande navio. Chega-se ao ponto em que se aceita, mesmo se espera, uma medida de identidade entre superioridade (de desempenho técnico) de armamentos, ou seja, a promessa tecnológica de tal desempenho, e a expectativa de sucesso no combate, na guerra (o cumprimento bem-sucedido da tarefa da defesa). Isso imiscui expectativas de diversas naturezas, a tal ponto em que não parece ser algo que se possa questionar sem alguma indução.

Num exemplo insuspeito do valor da percepção de Marshall MacLuhan de a mídia ser a mensagem ${ }^{5}$, considere-se a espetacularidade simples e direta do filme

5 McLUHAN, M. (2005) The Medium is the message. MIT Press, 2005, $160 \mathrm{p}$. 
de guerra prototípico, em sua cena mais incisiva para a questão do lugar e papel do armamento na guerra. Imagine-se a sequência:

- long shot, ambiente e personagens, as tropas em luta;

- zoom in, para o impacto que derruba um dos que a audiência já pensa como sendo um dos seus, com tudo o que isso tem de emocional;

- medium shot, a maior parte do corpo de um dos que a audiência já pensa como sendo um dos deles, o inimigo, com tudo o que isso tem de emocional;

- pan down, para perceber debaixo o esgar de satisfação do inimigo enquanto prepara mais um golpe;

- zoom out, se espera o pior para o galã, um dos nossos, que é o próximo alvo;

- medium shot, o golpe é desfechado;

- pan up que vê de cima o desapontamento do inimigo quando o golpe não produz efeito;

- zoom out, to medium shot do galá revelando que aparou o golpe;

- travelling shot que acompanha o galã enquanto converte a interceptação do golpe no início do contragolpe;

- medium shot, o contragolpe que derruba o inimigo;

- close up do fator explicativo da reversão da fortuna; e aqui se pode ter diversas possibilidades que acabam sendo a mesma.

A tal espada ou escudo, ou o que se coloca em tal lugar: o disparo mais intenso, a blindagem mais forte, o avião mais rápido, o navio mais imponente. Isso é acompanhado por efeitos visuais e sonoros diferentes dos que ocorrem na realidade. $\mathrm{Na}$ maioria dos filmes de guerra, o efeito especial que simula uma granada de mão usa uma carga explosiva bem maior e mais pirotécnica do que a granada possui, e se apõe à sua explosão um efeito sonoro menos intenso e mais agradável do que o que essa carga de efeitos especiais ou mesmo a explosão inicial produziria, por exemplo. E tem-se ainda o efeito indutor do fundo musical, que melhor cumpre o seu papel quando não é percebido conscientemente. ${ }^{6}$

A propaganda de produtos de uso de defesa é menos familiar que o cinema, mas manipula as mesmas ferramentas, e sabe-se das ferramentas da propaganda da experiência cotidiana. Não é preciso conhecê-la para reconhecê-la, numa diversidade de programas de aspiração educacional e de informação que a emulam, e em que a história da guerra é a sucessão de armamentos que se superam - por exemplo, o Weaponology do Discovery Channel ou o Future Weapons do History Channel. Há ainda a presença dessa falácia, precisamente porque ela é familiar, e porque ela é empurrada na lógica da mídia, em programas que não teriam a intenção de glorificar armamentos ou vender o que quer que seja. Ou ainda no

6 SUID, Lawrence H. (2002) Guts and Glory. The University Press of Kentucky, 2002, 768 p. 
noticiário que apresenta o armamento como sinônimo, símbolo, evidência do fato da luta, mas que pode muito facilmente reduzir a luta à alternância ou ao embate de armamentos - o que pode ser, aliás, precisamente o que a propaganda de guerra de um dos lados deseja.

Ensina-se assim que o resultado do combater é, principalmente, o resultado do embate entre os armamentos de que cada um dos lados dispóe. Derrota ou vitória dependem da posse do armamento superior. $\mathrm{O}$ resultado cumulativo das incontáveis ocasióes e maneiras como se teve essa vivência de segunda mão é um dos maiores empecilhos para que se possa vir a enquadrar, conduzir ou mesmo apreciar o papel da tecnologia na guerra. Contamina e interfere em qualquer tentativa de se considerar o que seja o processo pelo qual se perseguem promessas tecnológicas até que elas possam vir a permitir que se obtenham vantagens combatentes.

Tudo o que povoa esse imaginário é fake. Por mais familiar que seja, por mais habituado que se esteja a essa pseudorrealidade, é preciso trazê-la à mente para poder exorcizá-la. E isso pode mesmo ser simples, porque se pode colocá-la assim, despida da licença artística que a autoriza, sem o aparato da mágica do entretenimento ou da persuasividade medida da propaganda, até mesmo da ingenuidade que a toma apenas porque é mais fácil e familiar. E agora se pode dizê-lo, esperando ser entendido, de que não são os armamentos que lutam, mas as pessoas que lutam como eles. Que saber lutar é muito mais do que ter e usar o armamento. E daí denunciar a falácia reducionista, expondo como ela deseduca: ela ensina o desprezo ao trabalho do preparo da defesa, dos profissionais das armas, ao intimar que a posse deste ou daquele armamento, daquela tecnologia, é tudo o que é relevante.

Nas coxias do imaginário reducionista, ocultam-se a delicadeza, complexidade, duração e humanidade da luta, substituindo-as pelo espalhafato, simplicidade, concisão e automatismo que se consuma no embate entre armamentos. Os armamentos, os combatentes e as guerras não nascem do nada, não se resumem a uma frase ou duas que situam a ação, ou a uma tomada que alavanca familiaridade. É na História que se pode encontrar o processo de tomada de decisão pelo qual uma sociedade decide lutar, ou busca antecipar as circunstâncias e prover os meios de força com os quais pode vir a ter que lutar. Isso pode ter lugar muito antes que tais meios venham ser usados, ou pode se apresentar com a premência do imediato. Os meios de forças dependem, para existirem, do planejamento que organiza a conversão de recursos de toda ordem em grupos combatentes e sistemas de apoio, e daí em forças combatentes. ${ }^{7}$

A tecnologia não é em si mesma, não explica nada por si só: seu papel e efeito dependem de seu aproveitamento em algo material ou imaterial - um armamento, um arranjo, um procedimento ou um treinamento, por exemplo. Só quando se incorpora e aproveita tecnologia em artefatos, sistemas ou pessoas é que se pode

7 Cf. DELBRUCK, Hans. (1990) History of the Art of War, 4 vols. University of Nebraska Press, 1990; (2005) Delbruck's Modern Military History. University of Nebraska Press, 2005, 244 p. 
esperar que ela tenha significado para atividades e relacionamentos humanos. A tecnologia aplicada pode dialogar consigo mesma em alguma medida: os ganhos de desempenho entre diferentes possibilidades e aplicações tecnológicas. A medida comparativa desse desempenho referencia a aplicação tecnológica anterior, e se abre a apreciação de sua qualidade, por exemplo, em termos de benefício contra custo. ${ }^{8}$

Mas embora possa ser relevante, essa medida nunca é suficiente. Um ganho de desempenho palpável no depois em relação ao antes não se traduz, automaticamente, num ganho em capacidade combatente diante de um oponente. Não faz sentido considerar ou apreciar resultados tecnológicos em termos de capacidades, ou desempenhos técnicos, em si mesmos: tem-se que incluir sempre o oponente.

E agora talvez se possa apreciar que, ao contrário do que a falácia reducionista intima, a tecnologia não simplificou a guerra. Diferentemente do que se poderia, talvez, imaginar quando se tem como referência os últimos anos da digitalização no mundo civil, a tecnologia complicou extraordinariamente a condução da guerra nos últimos 100 anos. Cada novo desenvolvimento, cada novo armamento, sistema ou possibilidade de qualificação de pessoal exige não apenas o reaprendizado do fazer, mas principalmente um repensar. Esse repensar tem que considerar cada vez mais elementos e seus relacionamentos, impondo requisitos de qualificação técnica, tática e logística cada vez mais elevados. Não se trata apenas de rever o que o alcance ou o efeito deste ou daquele artefato, sistema ou procedimento significa para como se pretende lutar ou como se luta. A questão é propriamente cognitiva, a demanda por sínteses pragmáticas, que sejam capazes de produzir resultados. Sejam as sínteses que permitem formular doutrinas capazes de urdir artefatos, pessoal e procedimentos em grupos combatentes coesos e competentes, sejam as que capacitem ao exercício do comando. ${ }^{9}$

Esse turbilhão de desafios cognitivos e práticos não é algo recente. Que as coisas tenham que seguir mudando, porque mudam os artefatos e armamentos, mas para além deles, porque se aprendem acima de tudo formas novas de usá-los, e para usá-los depende-se de muito mais do que dos artefatos eles mesmos, é a principal lição da Grande Guerra de 1914-1918. Esse aprendizado impôs a necessidade de se considerar, de maneira articulada, o que sejam as escolhas de artefatos, armamentos e sistemas, de qualificação e articulação de pessoas e organizaçôes, de procedimentos e formas de agir - até mesmo as formas de lidar com a incerteza, a complexidade e a mudança que o estado da arte revela serem inescapáveis. ${ }^{10}$

Isso deu uma ênfase adicional para os processos cognitivos e práticos pelos quais uma sociedade converte alguns de seus recursos em meios combatentes e

8 PRZEMIENIECKI, J. S. (2000) Mathematical Methods in Defense Analyses. AIAA, 2000, 421 p.

9 MILLET, Alan R. \& MURRAY, Williamson. (2010) Military Effectiveness, 3 vols. Cambridge University Press, 2010.

10 JOHNSON, Stuart E.; LEVIS, Alexander H. (1988) Science of Command and Control Part I. AFCEA, 1988, 148 p.; JOHNSON, Stuart E. (1989) Science of Command and Control Part II. AFCEA, 1989, 180 p.; LEVIS, Alexander H. (1994) Science of Command and Control Part III. AFCEA, 1994, 191 p. 
arranjos de defesa: o projeto de força. O projeto de força é um dos elementos menos visíveis e mais capitais do relacionamento civil-militar. Trata-se da circunscrição da capacidade das forças armadas para que possam ser capazes de buscar os resultados que se esperam de seu uso, e para que não possuam capacidades que afrontem o que seja a preferência política de modos e métodos em seu uso. É nesse processo que se têm tanto o teste quanto o exercício da combinação das diferentes competências de órgãos de assessoramento do governo e das forças armadas. Isso depende de uma combinação delicada de aspectos cognitivos, técnicos e tácitos, para levar desde a meta de dispor de uma capacidade alinhada com a política de defesa até a materialidade da força pronta, capaz de agir, de combater com expectativa razoável de sucesso. ${ }^{11}$

Diante das metas da política de defesa de um governo, as forças armadas oferecem, usualmente, algumas alternativas de capacidade para a busca das metas de tal política, da forma como ela deseja buscá-las. O governo aprecia essas alternativas considerando suas preferências em termos do dispêndio de recursos ou de formas de sua administração como parte do aparato de Estado, e ainda em termos do que a gramática dos meios combatentes determina em termos de modos e meios. Em larga medida, o governo depende das alternativas de projeto que as forças armadas coligem. Assim, o projeto de força é uma instância em que se demanda a colaboração ativa das forças armadas para instituir os termos de sua própria capacitação e controle, seja para tarefas externas ou internas. ${ }^{12}$

Aqui se coloca, então, de maneira adequadamente modesta, o lugar das promessas tecnológicas, sejam as do presente, sejam as futuras. Em primeiro lugar, as forças armadas têm que ser capazes de identificar, apreciar e desdobrar as alternativas de que dispõem diante do estado da arte da gramática dos meios de força. É dizer, apreciar a tecnologia aplicada em termos de artefatos, sistemas, procedimentos, pessoal que correspondem à sua configuração existente, herdada de outro projeto de força. Suas propostas de alternativas de projeto de força dependem desse juízo e dos recursos que as forças armadas têm, esperam ou podem vir a ter, em função da decisão política. Em segundo lugar, apenas quando dispõem de tal inventário é que podem sopesar a oportunidade de configuraçôes alternativas de pessoal, artefatos e sistemas disponíveis para aquisição, por exemplo. Isso corresponde às promessas tecnológicas do presente. Em terceiro lugar, só com esses resultados podem vir a colaborar na identificação de carências ou oportunidades diante do potencial futuro desta ou daquela possibilidade tecnológica. Isso corresponde ao que se estime que sejam as promessas tecnológicas de futuro. ${ }^{13}$

Cada uma dessas perspectivas pode ter um papel mais ou menos relevante num determinado momento, num determinado contexto, em função do que seja a

11 Autor, 1998.

12 HICKS, Kathleen H. (2008) Invigorating Defense Governance. Center for Strategic and International Studies, 2008, 88 p.; LUSTGARTEN, Lawrence. (1986) Governance of Police. Sweet \& Maxwell, 1986, 168 p.

13 O’HANLON, Michael E. (2009) The Science of War. Princeton University Press, 280 p. 
política de defesa que esses esforços buscam permitir. Esse processo de participação no projeto de força é um dos mais importantes elementos de atualização cognitiva de uma força armada. Tem o papel de dinamizar e, portanto, de amenizar o efeito inercial que nasce da familiaridade com os arranjos e meios existentes, questionando-os.

Questionar-se não é fácil nem natural para forças armadas. Organizações de hierarquia vertical e com alto investimento em capital fixo tendem a ser avessas a algo que pode por em risco a fluência e familiaridade com o que têm. Mas o que promessas tecnológicas oferecem pode ser importante para a atualização, mesmo para a continuidade da capacidade de ação das forças. Isso faz com que tenham que considerar o que tem que ser mudado para que se possam manter capacidades comparáveis às do estado da arte dos meios e formas combatentes. Mas mudanças incrementais ou de partes podem cobrar um preço alto em termos de preparo ou de prontidão obtendo ganhos marginais de capacidade, pondo em dúvida o valor de promessas tecnológicas presentes ou futuras. O que seja o balanço entre essas duas tendências depende do que sejam os rumos e prioridades da política de defesa.

Como qualquer organização que não esteja adequadamente tutelada, as forças armadas sempre se arriscam a alguma forma de emancipação. Conveniências corporativas podem levar a desafios dos rumos da política, ou se prenderem a dinâmicas inerciais. Isso faz com que se possa lançar uma primeira luz sobre a dificuldade do processo de preparo de forças armadas em tempos de paz pela baliza de dois casos polares: a recusa e a sedução diante de promessas tecnológicas.

A recusa de promessas tecnológicas pode chegar ao extremo de preferir e demandar apenas mais do mesmo. Mais pessoal, que alarga possibilidades de progressão na carreira e aumenta o orçamento e o poder da organização tanto quanto de indivíduos em posições de mando. Mais ou melhores versões do que já se tem e conhece, que não ameaçam os arranjos existentes nem colocam desafios cognitivos para sua incorporação. A tecnologia é mantida à distância, ocasionalmente concedida em atividades-meio - que podem ser formas de um aumento indireto de recursos. Pode, ainda, ser confinada a uma pequena parte da força, onde fica indefinidamente experimental, expressando uma aceitação formal para ser uma recusa concreta.

A consciência do estado da arte pode ser deslocada para fora do âmbito cognitivo da força. Atua-se como se a tecnologia pudesse ser congelada num determinado instante, o que corresponde ao "do mesmo" que se tem e conhece. É uma forma de não ter que dar conta da infinidade de questôes que fazem parte do projeto e mesmo do preparo de uma força combatente. Em vez de se ter que lidar com os problemas concretos e em movimento do estado da arte, pode-se priorizar problemas em termos familiares e fixos, dando-os como resolvidos. Nesse caso, é bem mais fácil chegar a resultados incontestes, e mesmo consensuais, já que tais resultados ganham a força da longevidade, e seu questionamento é o questionamento dos resultados de quem tem a ascendência da hierarquia. Quanto 
mais os conflitos intraforça se sobrepõem a disputas interforça, mais sedutor se torna ofertar alternativas para o projeto de força que são apenas réplicas e expansões do que a força já é, ou imagina ser. O rumo do conjunto e a integração da ação das forças ficam entregues às formas de justaposição mais brandas que se possa obter da autoridade civil. ${ }^{14}$

A ausência de tutela pode levar à outra forma de emancipação, em que se abraça a promessa tecnológica. O "mais do mesmo" é substituído pelo "nada será como antes". Isso não é um paradoxo: a aversão a mudanças incrementais ou a rearranjos substantivos de partes pode levar a apostas em promessas tecnológicas, mesmo quando elas carecem de outro respaldo que não o de sua ambição ou sedução. Aqui a tecnologia é tomada como uma panaceia. Essa postura tem o benefício de desautorizar o questionamento: o que seja a visão desse dever-ser está condicionada apenas pelo que interesses intraforça possam entrever e ambicionar. Ao se lidar com uma visão, com um dado porvir, admite-se necessariamente uma medida de sonho, e isso permite ainda a demanda corporativa de alinhamento afetivo com essa uma determinada ambição. É como se a capacidade não precisasse ser mais do que promessa, ficando sempre no futuro.

Ao viver no futuro, a força não precisa dar conta da infinidade de questóes que fazem parte do processo de projeto e preparo de uma força combatente. Em vez de se ter que lidar com problemas concretos, pode-se priorizar problemas imaginários. Neste último caso, é bem mais fácil chegar a resultados incontestes, e mesmo consensuais, já que tais resultados dependem apenas do acordo dos envolvidos e podem mais facilmente serem feitos segredos ou obrigaçōes profissionais. Quanto mais os conflitos interforças se sobrepõem a disputas intraforça, mais sedutor se torna ofertar alternativas de projeto de força que apostam inteiramente no que uma promessa tecnológica permitiria fazer. O rumo do conjunto e da integração das forças se faz uma prenda em disputa, a ser obtida por uma das forças por sobre as demais, de forma tão avassaladora quanto se possa obter da autoridade civil. ${ }^{15}$

Em ambos os casos, a menos de uma capacidade civil em defesa capaz de ter juízo próprio sobre as alternativas apresentadas diante do estado da arte, isto é, capaz de exercer uma tutela substantiva, chega-se muito rapidamente a disfunções. A capacidade combatente das forças fica refém de dinâmicas corporativas. Quando isso acontece, a rotina administrativa se sobrepõe, podendo mesmo excluir, o exercício e o experimento de que a integridade do preparo depende. O emprego é algo mantido à distância de processos de avaliação e autoaperfeiçoamento. Tem-se pouco ou nenhum interesse em manobras que podem relevar problemas. O preparo se confina à adesão, por vezes apenas nominal, a um determinado padrão longevo ou projetado. O teste dos arranjos combatentes e de defesa diante de tal

14 POSEN, Barry R. (1986) Sources of Military Doctrine. Cornell University Press, 288 p.

15 MacISAAC, David. (1986) "Voices from the Central Blue" in PARET, Peter, Ed., Makers of Modern Strategy. Princeton University Press, 1986, p. 116-42. 
padrão pode degenerar numa encenação que valida o que se acredita ou se espera ter ou ser. Tem-se muitas atividades, mas nenhum problema: seja porque se espera mais do mesmo, seja porque se espera a vinda do inédito transformador. Mas pode ficar difícil identificar ou aferir atividades cuja medida seja a disponibilidade de capacidade pronta e concreta à luz do que seja o estado da arte.

Uma das tarefas mais difíceis na direção das forças armadas é resistir às pressões inerentes da dinâmica burocrática de sua dimensão e complexidade. Estas pressionam pela aparência de conformidade com mais facilidade do que por esforços que se mensurem por desempenho real. Sem tutela civil que o exija, ou oponente que o exponha, é fácil confiar em excesso no que parece correto ou apenas concorda com o que se imagina ou deseja, e que só esteja ao alcance do "militar". Esse potencial de autolocupletação não tem como ser inteiramente contido pelas forças elas mesmas. ${ }^{16}$

Em tempos de paz, a tutela civil tem que ser capaz de impor dinâmicas capazes de permitir espaços em que se admita o questionamento da maneira de pensar, de agir e mesmo de ser das forças enquanto organizações burocráticas. Os últimos 50 anos deram conta de diversos ciclos e enormes esforços em busca de formas de integração das forças, seja em termos de sua ação integrada (joint), seja em termos de contatos vivificantes entre os sistemas de educação, mais amplamente de preparo militar, com a dinâmica do mundo civil, por exemplo, com a universidade. Essa é uma obra em andamento, que tem sua própria história e detalhes, e não pertence a este artigo. Aqui é suficiente ter apontado que a integração interforças e a qualidade cognitiva das forças faz parte do projeto de força.

Em tempos de guerra ou crise, essas questóes ganham diferentes qualidades. Diante do oponente, em armas, na luta iminente ou presente por coisas que importam, se descobre nele um excelente tutor, ainda que, como aponta Tucídides, a guerra seja uma mestra violenta. E aqui se tem, para fazê-la explícita, a razão de ser de toda a discussão: a impotência diante do oponente por desvãos de falta de tutela na paz pode pôr em risco a prosperidade, a democracia, a soberania e mesmo a independência de um povo.

\section{Aproveitamento tático do desempenho técnico}

Que se possa vir a ter vantagens combatentes a partir de promessas tecnológicas é o que anima uma grande parte do projeto de força, e isso depende da exploração do desempenho técnico de artefatos, sistemas e pessoal. Mas vantagens combatentes não se apresentam espalhafatosamente, não são automáticas, nem são certas ou permanentes. Seu uso não é autoevidente e elas dependem da vontade e habilidade

16 BRUNEAU, Thomas C.; TOLlEFSON, Scott D., Eds. (2008) Who Guards the Guardians and How. University of Texas Press, 336 p. 
humana na luta, no combate. Vir a ter tais vantagens depende do empenho, trabalho e arte dos combatentes eles mesmos - os estudos de estado-maior, os experimentos e experiências dos profissionais, a rotina do preparo, exercício, experimento, o aprendizado na própria luta. É nesses que se pode vir a identificar o potencial de arranjos táticos ou logísticos que possam vir a produzir vantagens combatentes. A delicadeza do processo sugere que se aponte aquilo sobre o que se deveria pensar de forma mais adequada por meio de uma ilustração. Propõe-se assim ilustrar o aproveitamento combatente do desempenho técnico, o lugar da tecnologia na guerra, escolhendo como foco a produção de vantagens táticas, no combate, isto é, a promessa tecnológica de armamentos. Enfrenta-se assim a falácia reducionista ali onde ela promete certeza.

Apresentam-se apontamentos sobre desempenho técnico e aproveitamento tático dos diferentes fuzis utilizados nas guerras da Prússia contra a Áustria em 1866, e contra a França em 1870. Seu interesse está em que se trataria, na lógica do espalhafato, de aspectos menores; de mudanças que nada tiveram de espetaculares. Expressaram escolhas dos países envolvidos num ambiente de normalidade de despesas e transparência de suas alternativas e decisóes. Mas ainda assim produziram o efeito de dar a um dos lados vantagens substanciais.

Em 1866, vantagens combatentes da infantaria prussiana que exploraram a superioridade de desempenho técnico de seu fuzil - a promessa tecnológica: um desempenho técnico superior do armamento que produziu sucesso.

Em 1870, vantagens combatentes da infantaria prussiana que exploraram a inferioridade de desempenho técnico de seu fuzil - o questionamento de tal promessa: um desempenho técnico superior do armamento que produziu fracasso.

Eis o que se deseja apresentar: que se pode produzir vantagens combatentes tanto com o benefício quanto contra resultados tecnológicos, diante de superioridade e inferioridade de desempenho técnico de artefatos, porque vantagens combatentes são mais do que apenas o que se pode ter em promessas tecnológicas. E não se tem aqui casos restritos e pedantes, de pouco interesse: essas foram as guerras que fizeram surgir a Itália e a Alemanha modernas, onde o que se fez com fuzis levou à reconfiguração do equilíbrio do poder na Europa e pautou a História do século 20.

A Guerra Austro-Prussiana de $1866^{17}$ colocou Prússia e Piemonte (que aspirava ser, e já se denominava, "Itália") contra a Áustria, para forçá-la a abandonar seu pleito de autoridade sobre terras alemãs e italianas. Para os fins deste artigo, é suficiente apontar que os exércitos principais de Prússia e Áustria se buscaram nas províncias austríacas da Silésia e Boêmia. A campanha progrediu de uma sucessão de refregas de crescente intensidade entre as vanguardas, com desconcertante vantagem prussiana, até uma grande batalha das forças principais em Königgrätz. Nessa batalha, a força austríaca foi expulsa da posição forte em que esperava vencer os prussianos com tais perdas que a Áustria cedeu tudo o que dela se queria.

17 WAWRO, Geoffrey. The Austro-Prussian War. Cambridge University Press, 330 p. 
Muito do sucesso prussiano nessa campanha resultou da superioridade tática de sua infantaria. E aqui se pode começar a considerar o papel do armamento, portanto da tecnologia, daí de promessas tecnológicas. A partir de 1848, os prussianos haviam rearmado sua infantaria com um dos primeiros fuzis de repetição, o Dreyse Zündnadelgewehr de 1841, que disparava 10 a 12 vezes por minuto com um alcance de $600 \mathrm{~m}$. Os austríacos tinham considerado uma mudança equivalente no armamento de sua infantaria em função de suas experiências na Guerra de 1859 contra Piemonte, em que tinham tido contato com o Dreyse das tropas de Garibaldi. Consideravam que o maior volume de fogo do Dreyse seria compensado pelo maior alcance, de $900 \mathrm{~m}$, de seus fuzis Lorenz (de 1855) e Augustin (de circa 1840), apesar de esses dispararem apenas 3 a 4 vezes por minuto: em vez de disparos rápidos e independentes, tiros pausados e coordenados, em salvas demolidoras. Ajuizaram, assim, que a vantagem não valia o preço do rearmamento e o esforço de uma mudança em seus arranjos: um armamento que disparava quatro vezes mais depressa exigiria um repensar de seus arranjos - táticos para poder ser usado no combate, ou logísticos, como, por exemplo, a expectativa de ter que fornecer quatro vezes mais munição.

Aqui se chega ao cerne da questão. Os austríacos estavam errados, mas também estavam certos. O porquê de estarem errados e certos ilumina o problema do aproveitamento tático de desempenho técnico e, portanto, a origem e uso de vantagens combatentes. Por um lado, a cadência de tiro do Dreyse não tinha como ser aproveitada nos arranjos táticos de inspiração napoleônica que predominavam em meados do século 19. A linha de tiro, ombro a ombro, disparando em salvas, desperdiçava o potencial do volume de tiros que se podia produzir com cada combatente atirando individualmente. As colunas de marcha ou assalto simplesmente impediam a maioria dos combatentes de atirar e eram alvos fáceis e frágeis. Os prussianos adotaram estrutura de comando, organização logística e abordagem tática que enfatizavam a dispersão, a mobilidade e a iniciativa para aproveitar o que o Dreyse permitia. Cada fração de 100 ou 200 combatentes que tivesse o oponente a seu alcance abria fogo, empastelando o oponente com tiros, disparando tão rápido quanto possível. Assim que pudesse, seguia adiante, sem esperar apoios ou reforços, forçando seu avanço formação oponente adentro, atirando sem parar. Os austríacos não encontraram resposta para o volume de fogo, a celeridade e ímpeto com que cada fração de tropa prussiana se lançava ao combate. Para lutar, os austríacos dependiam da articulação de ao menos algumas centenas, idealmente de milhares de combatentes numa determinada formação, apoiando-se mutuamente. O ímpeto e o fogo prussianos impediam que pudessem chegar a tal formação. Como resultado, nas refregas e escaramuças, os austríacos foram sobrepujados.

Por outro lado, os prussianos descobriram que, numa grande batalha, a solidez das formaturas austríacas e o alcance de suas salvas permitia-lhes lutar de maneira a frustrar a aproximação prussiana. Fora do alcance ou ao abrigo da 
chuva de projéteis do Dreyse, uma posição austríaca não tinha como ser vencida pelo fogo ou ímpeto da infantaria prussiana. Era capaz de devolver os golpes, explorando o alcance e o peso de fogo de suas salvas. Em Königgrätz a infantaria austríaca foi capaz de conter e enfrentar a prussiana, permitindo que sua artilharia, em particular, pudesse participar da luta. $\mathrm{O}$ desenrolar da batalha de Königgrätz revelou que ainda havia muito em favor dos arranjos napoleônicos numa grande batalha. Os austríacos, com seus milhares onde deveriam estar, mostraram que suas linhas de fogo, suas marchas de apoio e seus arranjos de comando de milhares e de artilharia eram superiores quando podiam se apoiar mutuamente. Königgrätz não foi uma vitória fácil: foi uma luta dura e apertada. Os prussianos sofreram para arrancar uma vitória quando o fracionamento e ímpeto que tanto lhes serviram antes produziram riscos consideráveis e perdas desnecessárias. Que tenham vencido resultou tanto de sua habilidade em reinventar o uso do que o Dreyse permitia para uma grande batalha quanto da inabilidade dos austríacos de aproveitarem plenamente suas próprias vantagens antes que os prussianos aprendessem, ali, em plena luta, no transcurso de um único dia, como dar conta delas.

A Guerra Franco-Prussiana de $1870^{18}$ colocou a Prússia, à testa da confederação da "pequena Alemanha" (porque, como resultado de 1866, a Prússia excluíra a Áustria da "Alemanha"), contra a França. Foi o resultado de uma artimanha política em que a guerra foi o instrumento da superação das resistências dos Estados alemães confederados a serem unificados num Império Alemão sob a Prússia. Para os fins deste artigo, é suficiente apontar que os exércitos principais de Prússia e França se buscaram nas províncias orientais da França. Como resultado do processo de mobilização e disposição inicial de ambos os lados, os prussianos foram capazes de lançar o grosso de sua força contra uma parte da dos franceses. A campanha se iniciou com refregas de moderada intensidade e batalhas em que a Prússia saiu vitoriosa, mas estas foram vitórias amargas. Os prussianos sofreram baixas pesadas e desproporcionais, a despeito de sua superioridade numérica. No entanto, a partir de certo ponto, as vitórias prussianas passaram a ser menos custosas e isso lhes permitiu dividir, derrotar e isolar as forças francesas até a sua derrocada.

Muito do amargor das primeiras vitórias prussianas resultou da inferioridade tática de sua infantaria. E aqui se pode começar a considerar o papel do armamento, portanto da tecnologia, e daí de promessas tecnológicas. Os prussianos seguiram usando o Dreyse e, vaticinados por sua experiência em Königgrätz, concentraram seus esforços de modernização na artilharia e na adaptação das formas napoleônicas de grandes batalhas para o que os armamentos de que dispunham permitiam. Os franceses, a seu turno, tinham levado um susto e tanto com a vitória prussiana de 1866. Estavam cientes de que o que acontecera com a Áustria teria sido o seu destino caso a guerra tivesse seguido em sua direção. Empenharam-se energicamente em modernizar o armamento de suas forças adotando - no que interessa a este artigo

18 WAWRO, Geoffrey. The Franco-Prussian War. Cambridge University Press, 342 p. 
- um novo fuzil em 1866. O Chassepot tinha um alcance de $1.200 \mathrm{~m}$ e podia disparar 30 vezes por minuto; por breves momentos, podia disparar um tiro por segundo, o equivalente a 60 disparos por minuto. Tinha, portanto, o dobro do alcance e de 2 a até 5 ou 6 vezes a cadência de tiro do Dreyse. Os franceses tinham confiança de que, com tal armamento, sua infantaria faria com a prussiana o que esta havia feito com a austríaca.

Aqui se chega ao cerne da questão. Os franceses estavam certos, mas também estavam errados. O porquê de estarem certos e errados ilustra o aproveitamento tático de desempenho técnico e, portanto, a origem e uso de vantagens combatentes. Por um lado, a superioridade de desempenho do Chassepot era acachapante. Tentativas prussianas de chegar a um alcance em que a tempestade de tiros do Dreyse pudesse ter lugar produziram banhos de sangue, exigindo recuos e impondo baixas desmoralizantes nas fraçôes de tropa prussiana que o intentaram. Mesmo quando os prussianos reuniam mais tropas e conseguiam se aproximar o suficiente para poderem usar o Dreyse, aceitando o preço de suas baixas na aproximação, na troca de tiros a curta distância o Chassepot era claramente mais capaz que o Dreyse. A tomada das posições francesas exigiu enorme superioridade numérica, o manejo de tropas na lógica da grande batalha e, ainda, a aceitação de baixas desproporcionais às francesas. Os prussianos amargaram esse preço porque sabiam que tinham conseguido concentrar quase toda a sua força contra uma parte da dos franceses. Se as coisas tivessem ficado assim, os prussianos, sofrendo bem mais perdas do que produziam, teriam que reconsiderar suas expectativas de sucesso na guerra - não haveria como vencer a força principal dos franceses.

Por outro lado, os franceses não tinham, realmente, ido muito além da simples adoção do Chassepot. Haviam atualizado seu armamento, sim, mas apenas isso. A estrutura de comando, organização e formações de luta francesas eram basicamente as mesmas de Bonaparte, cujo armamento havia sido mosquetes de alcance de $50 \mathrm{~m}$ e cadência de tiro de 2 ou 3 tiros por minuto: alguns poucos atiradores independentes adiante, que só atiravam em alvos mirados, deliberadamente; linhas de tiro, ombro a ombro, que disparavam em salvas; colunas de marcha compactas para dar ou receber apoio; densas colunas de assalto para atacar à baioneta - tudo como fizera Bonaparte. Só que as táticas que haviam servido quando o armamento era o mosquete não eram mais possíveis diante de fuzis de repetição: estes podiam liquidar os atiradores independentes, empastelar as linhas ou aniquilar as colunas que ficassem a seu alcance. Os franceses descobriram que não tinham pensado em formas de lutar que usassem o alcance ou a cadência de tiro do Chassepot. Suas formaturas e procedimentos só admitiam uma disposição concentrada que desperdiçava o potencial do armamento de que dispunham, e os improvisos de que lançaram mão numa ou noutra ocasião não foram suficientes. Os prussianos perceberam que podiam contornar as formaçōes e os dispositivos franceses ficando fora do alcance dos tiros do Chassepot, cercando-os e cortando suas linhas de retirada e abastecimento. Uma vez cercadas e isoladas, as tropas francesas se 
sabiam condenadas. Quando contra-ataques franceses tentaram romper o cerco, os prussianos aprenderam a aceitar baixas em sua infantaria sob o fogo inicial do Chassepot, porque assim que os franceses chegavam ao alcance dos Dreyse (ou a renovada artilharia prussiana podia intervir, pelo mesmo motivo que em Königgrätz), o fogo prussiano aniquilava suas formações.

Do momento em que as batalhas se transformaram em disputas desse tipo, em que a superioridade de enfoque prussiana no uso do que seu armamento permitia se afirmou sobre a adoção inercial de armamento pelos franceses, as diferenças de desempenho dos fuzis se revelaram um detalhe relevante, ao invés de um fator determinante. Então foram as baixas francesas que se tornaram insuportáveis, e eles não tiveram a oportunidade de elaborar uma resposta antes do fim.

Essa ilustração pode servir para situar o que quer que venha a ser o processo, o resultado ou o uso de promessas tecnológicas em diversas instâncias e formas de materialização. $\mathrm{O}$ combate e a guerra são embates de forças vivas, a luta de pessoas e não de tecnologias em potencial, em abstrato, nem mesmo apenas de artefatos ou sistemas concretos em que tal tecnologia se encontra aplicada. $\mathrm{O}$ aproveitamento tático de desempenho técnico depende de mais do que a posse deste ou daquele armamento com um determinado desempenho, mesmo que ele seja taticamente útil - um fator substantivo da capacidade combatente. Obter e usar vantagens combatentes depende de todo o trabalho, antes e mesmo durante o desenrolar da luta, que permite converter capacidades e possibilidades em vantagens. Inclui ser capaz de encontrar formas de explorar tais vantagens em resultados na luta contra determinado oponente, num determinado contexto, diante das vantagens que o oponente pode ter. Apenas quando se considera esse todo é que se pode trazer os elementos que explicam o aproveitamento de desempenho técnico em vantagens combatentes de maneira íntegra.

\section{Considerações finais}

Um elemento final precisa ser apontado: o risco de que o enquadramento do processo que leva da percepção de promessas tecnológicas até a posse de capacidades combatentes prontas possa se enrijecer, fazendo-se uma formalidade a mais, um formulário burocrático adicional a ser marcado e esquecido. $\mathrm{O}$ aprendizado que permite identificar, desdobrar e usar vantagens combatentes só pode ser adquirido e mantido vivo nas organizações e pessoas pela prática, pelo exercício e pela crítica que nasce da articulação entre estudo, experimento e experiência. Só assim se pode superar a reificação do vivido ou experimentado, convertendo-os em empiria capaz de sustentar o aperfeiçoamento. Sem isso, arrisca-se ficar refém da expectativa de que uma vez feito, se tenha um resultado permanente e perfeito, que não demanda outro ensaio e não admite questionamento, quando então o oponente pode ter outra perspectiva da questão. A imperenidade de qualquer vantagem combatente 
é bastante evidente. Ela depende tanto do contexto quanto das capacidades comparadas. Aprender a identificar possibilidades pela imaginação e o rigor do estudo em lutas virtuais é o pré-requisito de poder fazê-lo quando a luta for real. Sem o trabalho intelectual e prático constante, alerta, questionante, que faz com que reconhecer e saber usar uma vantagem seja parte integrante do preparo, pode ser temerário presumir que tal habilidade esteja presente no momento do emprego. ${ }^{19}$

O processo que leva de possibilidades tecnológicas a vantagens combatentes é, por sua própria natureza, uma obra inacabada. Não poderia ser de outra maneira, porque depende de escolhas que compõem alternativas de lógica política e da gramática dos meios. Ele segue, num sentido essencial, por fazer até o instante em que se segue adiante com o que se possa ter para arrancar a vitória, quando então se pode ter que repensar e refazer - mais de uma vez, e mesmo diante do oponente. A tutela civil tem que ser capaz de impor dinâmicas que conduzam e apoiem o cerne de capacidade combatente das forças, impedindo que este se paralise em dinâmicas burocráticas, autocomplacentes e satisfeitas. Mas esse é um limite do que se pode fazer em antecipação e tal limite é, ele mesmo, uma perspectiva necessária para que possa enquadrar e compreender esse processo. Depende-se do resultado concreto do trabalho diuturno e qualificado dos profissionais das armas, e do que se possa fazer para apoiá-los de maneira crítica e substantiva - seja no projeto de força, seja no processo de descoberta de oportunidades das quais se pode extrair vantagem - na temporalidade que os fatos exigirem.

Recebido em 8 de maio de 2011 Aprovado em 19 de agosto de 2011

\section{Resumo}

Para compreender como se vai desde promessas tecnológicas presentes ou futuras até a disponibilidade, pronta e concreta, de vantagem combatente, este artigo enquadra tal processo como a articulação da lógica política com a gramática dos meios de força. Apresenta-se uma ilustração histórica que busca trazer à mente algumas coisas sobre as quais se pensar.

Palavras-chave: defesa; estudos estratégicos; tecnologia.

\section{Abstract}

This article outlines the process that can lead from present or future technological promise to ready and palpable fighting advantage, seeing its management as an expression of the connection between the logic of politics and the grammar of the means of force. A historical illustration brings to mind some things worth thinking about.

Keywords: defense; strategic studies; technology.

19 WAWRO, Geoffrey. Warfare and Society in Europe, 1792-1914. Routledge, 256 p. 